\title{
Outlining the impact of intellectual capital accumulation and depletion processes on the performance of an insurance firm: a dynamic resource-based perspective
}

\author{
Enzo Bivona*
}

Ricevuto il 30 Giugno 2013

Accettato il 23 Luglio 2014

\begin{abstract}
This paper aims to develop a conceptual framework on how Intellectual Capital (IC) accumulation and depletion processes are dynamically interrelated with firm performance. Such a framework makes explicit the relationships between policy levers, strategic resources, drivers, end-results and performance indicators through a Dynamic Resource-based perspective. Such an approach matches the Resource based perspective and the System Dynamics (SD) methodology. This paper argues that in order to explain a firm superior performance, it is not sufficient to look at the endowment of strategic resources in a given moment of time; it is instead required to investigate the dynamics of company strategic resources accumulation and depletion processes over time and how such assets are interconnected with the critical success factors which may enable the firm to build a sustainable competitive advantage. To this aim the proposed conceptual framework was applied to an insurance firm. The paper also highlights the benefits of the developed SD simulation model to support decisions makers' learning processes in planning alternative IC investment policies.
\end{abstract}

Keywords: Intellectual Capital; Resource Based View; System Dynamics; Dynamics Resource-based perspective; performance measurement.

\section{Introduction}

The performance of a service business mostly relies on the ability of both the personnel and the organization to timely meet customers' requests

* Assistant Professor in Business Management, University of Palermo (Italy), Faculty of Political Sciences, $\mathrm{PhD}$ in Business Management, University of Catania (Italy), Master Phil. in System Dynamics, University of Bergen (Norway), enzo.bivona@unipa.it, University of Palermo-System Dynamics Group. 
and to satisfy their changing needs. In such context, the Intellectual Capital (IC), i.e., human resource and firm knowledge, is often conceived as a fundamental strategic resource on which to pay great attention as primary source of company competitive advantage, difficult to imitate by rivals.

To investigate how IC and, in general, strategic resources are able to maintain a superior performance the Resource Based View (RBV) of the firm is very often adopted (Penrose, 1959; Wernerfelt, 1984; Barney, 1991). According to such a perspective, a firm' superior performance relies on a unique bundle of strategic tangible and intangible resources, difficult to imitate and non-substitutable. The RBV of the firm has been highly criticized in literature as it approaches the study of the competitive advantage sources primarily from an internal perspective, neglecting the industry forces in which the firm operates.

This paper argues that to explain a firm performance is not sufficient to look at the endowment of strategic resources, but it also requires an analysis of the internal and external forces that are likely to influence the strategic assets accumulation and depletion processes. In order to test such a hypothesis a conceptual framework to investigate IC accumulation and depletion processes is provided.

This framework aims to explore the impact of IC investments on strategic resources, drivers, end-results and performance measures through a dynamic resource-based perspective (Warren, 2002, 2008; Bianchi and Bivona 2005; Bivona 2008; Bianchi, 2012). In particular, the use of the System Dynamics (SD) methodology (Forrester 1961; Sterman 2000) allows to make explicit cause-and-effect relationships underlying the investigated phenomenon and to built simulation models through which assessing alternative scenarios.

In order to test the above framework, an empirical research was conducted with the support of an insurance company. Such a context provided the basis to develop a SD model to outline IC accumulation and depletion processes and their impact on firm performance.

The paper is divided into five main parts.

In the first part, a literature review of the concept of IC as strategic resource to build a sustainable competitive advantage is provided. Advantages and drawbacks of main IC frameworks provided in literature are also briefly discussed.

In the second part, the framework aimed at exploring the impact of IC investments on strategic resources, drivers, end-results and performance measures through a dynamic resource-based perspective is outlined.

In the third part, the suggested framework is developed with reference to an insurance firm. Such empirical analysis provided the information to build a SD model to outline IC accumulation and depletion processes. 
In the fourth part, results of two alternative IC investments policies through the use of the SD model are commented.

Finally, conclusions and further research are discussed.

\section{The intellectual capital: a strategic resource to build a sustainable competitive advantage}

To maintain a superior performance and a competitive advantage - in terms of unique configurations of resources difficult to imitate by rivals $-\mathrm{a}$ growing number of firms focuses its attention on investments in strategic assets, which are often intangibles. Intangible assets refer to variables such people and their experiences, business processes and routines, company reputations and image. In contrast with tangible assets, intangibles are very seldom displayed on company balance sheet such as equipment, buildings and products inventory. Intangibles are also very complex to manage, as it is difficult to monitor their current status and to develop managerial policies able to directly impact on them.

During last two decades, an intangible strategic asset that has been particularly investigated is the Intellectual Capital (IC). IC refers to the possession of knowledge, applied experience, organizational technology and customer relationships which enable a company to achieve a superior competitive position (Edvinsson \& Malone, 1997) and to build a sustainable competitive advantage.

The field of IC revels a general agreement about the strategic importance of such assets on firm performance (Menor et al, 2007; Hsu and Sabherwal, 2011). However, a consensus cannot be deeply detected in terms of unitary IC definition neither in terms of common frameworks and models aimed to assess and measure IC. The author argues that such differences represent a source of complexity in fully understanding and properly managing IC assets dynamics. For this reason, it is important to briefly review the evolution of the IC definitions and frameworks/models provided in literature ${ }^{1}$.

According to Stewart (1997) IC refers to intellectual material, such as knowledge, information, intellectual property and experience that can be put to use to create wealth; Brooking (1996) outlines the central role played by the relationship between market, human-centered, intellectual property and infrastructure assets to build IC; Lev (2001) defines IC as a non-physical sources of

\footnotetext{
${ }^{1}$ The aim of the paper is far beyond an exhaustive review of the IC definitions and frameworks/models provided in literature. For a deeper literature review, the reader can refer, among the others, to Marr (2005), Andriessen (2004) and Choo and Bontis (2002).
} 
value (claims to future benefits), generated by innovation (discovery), unique organizational designs, or human resource practices, which is more than the sum of human, structural and relational resources of the firm.

IC definition problems also occur as different perspectives or disciplines (economics, strategy, accounting, finance, marketing, human resources) approached this field (Bontis 2002; Maar 2005).

The review on IC frameworks (Andriessen, 2004), as reported in figure 1 , shows a common agreement to divide IC into two or three main elements: human capital, structural (or organisational) capital, and relational (or customer) capital.

\section{Figure 1 - Intellectual Capital classification}

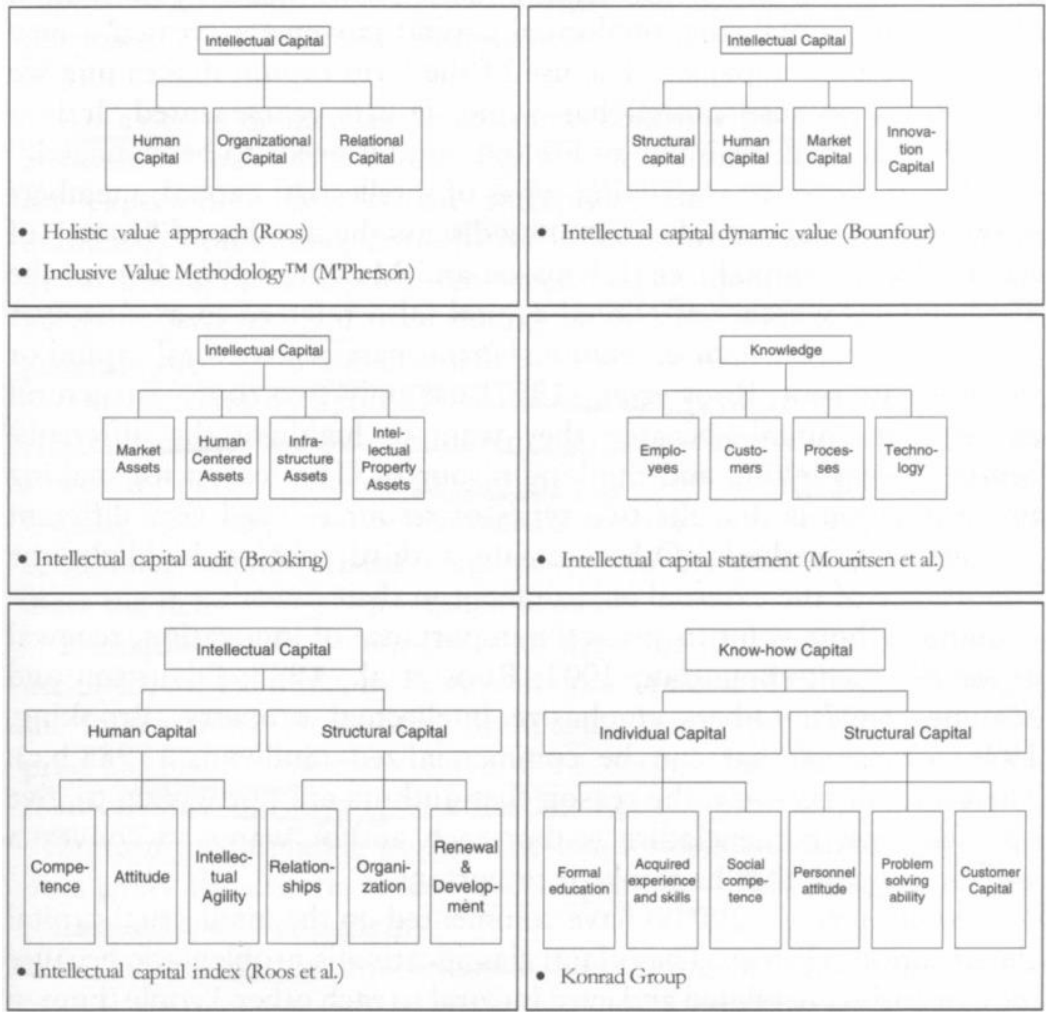

(Source: Andriessen 2004, p. 61).

In the last two decades several frameworks for managing IC have been developed in both academic and practitioner fields. These frameworks include The Skandia IC Navigator (Edvinsson and Malone, 1997), the Intangi- 
ble Assets Monitor (Sveiby 1997), the Value Chain Scoreboard (Lev 2001), the Meritum (Meritum, 2002) and the Danish (DMSTI 2003) guidelines and The Value Creation Map (Marr et al., 2004) and some others (Marr, 2005; Lönnqvist et al., 2009; Dumay 2009; Pasher and Ronen 2011).

IC models evolved from quantitative measures to those combining monetary and, in particular, non-monetary indicators able to monitor the ability of a firm to accumulate IC, as a key factor to build a sustainable competitive advantage (Porter, 1985).

To develop the IC of a company in order to be competitive in a given environment, The Skandia IC Navigator (Edvinsson and Malone, 1997) suggests to develop a set of measures in five different areas (financial, customer, process, human and renewal \& development). The navigator aimed to provide a quick judgement of a company's IC strength, which is essential for the creation of a future value. Skandia Navigator's advantages to combine financial and nonfinancial measures are tackled by the high range and subjectivity of the selected performance measures (91 IC plus 73 traditional metrics) and the static perspective of the framework. In particular, it has been emphasized (Roos et al., 1997) that following a balance sheet approach the navigator offers only a snapshot in time and cannot represent the dynamic flows of an organization.

The Intangible Assets Monitor (IAM) is a method for measuring intangible assets (Sveiby, 1997). It is based on three families of intangible assets: employee competence (ability to act in a variety of situations to create both tangible and intangible assets), internal structure (organisational culture, patents, concepts, models, computer and administrative systems) and external structure (customers and suppliers relationships, brands, trademarks and company image). For each intangible assets Sveiby (1997) proposes to select one of two indicators of growth/renewal, efficiency and stability. Main innovation in the suggested framework consists in the shift of the focus from stock to flow variables to measure intangible assets. However, main drawbacks do not reside in the hard task to design the suggested measures, rather on how to connect in a cause-and-effect relationship outcomes and changes in the business performance, so that decision makers can clearly act on the proper policy levers to influence results.

The Value Chain Scoreboard (Lev 2001) focuses on the process of innovation, for instance, of new products or services, as it is considered essential for the survival and the success of an organisation. It aims at providing an information system for both internal decision-makers and external investors. The value chain identifies three phases related to the process of innovation: discovery and learning, implementation and commercialisation. For each phase, three additional categories are outlined, respectively: 
- internal renewal, acquired capabilities and networking;

- intellectual property, technological feasibility and internet;

- customers, performance and growth prospects.

To monitor the innovation process, for each of the nine portions of the scorecard a variety of indicators can be chosen. However, to ensure scorecard's usefulness, indicators have to satisfy three conditions: they should be quantitative, standardized and resulting from empirical evidence. Such criteria should be able to also support decision makers to carry out a comparison across firms and to link the indicators to corporate performance. Contrary to the previous framework (see for instance the Skandia case), the value chain does not emphasise the role of human capital per sè, but it focuses on the formal processes of knowledge generation.

The guidelines developed by the Measuring Intangibles to Understand and Improve Innovation Management project (MERITUM, 2002) and the Danish Ministry of Technology and Innovation (DMSTI, 2003) focus their attention instead on processes (actions/initiatives) aimed to build the required endowment of strategic tangible and intangible (in particular IC) resources to implement a desired strategy. These frameworks also provide a system of indicators to monitor the success of the firm to implement a given strategy. However, the cause-and-effect relationships between actions/initiatives and the accumulation and depletion processes of company strategic assets are not explicitly addressed. Although causal ambiguity may exist between variables (Nørreklit, 2000), denying such cause-andeffect relationships may prevent decision makers to learn how to allocate resources to achieve desired goals.

To address such a gap, more recently, a cause-and-effect approach has been developed to make explicit the net of relationships between tangible, intangibles and IC strategic resources and how they are likely to influence organisational value creation. The Value Creation Map (Marr et al., 2004) visualises, through the difference in size of the arrows, the influence of the variable "cause" on the variable "effect". However, two aspects require particular attention.

First, if the use of arrows of different size allows decision makers to visualise the importance of causal relationships between variables, the absence of indicators prevents the measurement of the effects produced by management decisions.

Second, the link between a "cause" variable (e.g., know-how) and the "effect" variable (e.g., patents) is not a static, but a dynamic relationship, whose intensity may change over time. For instance, a low endowment of know-how may produce an inconsistent effect on patents. However, a con- 
tinuous increase in know-how does not necessarily imply a proportional grow in the number of company patents. More likely such relationship is characterised by a so called S-shaped curve behaviour (Rogers, 1962), which can be divided in three different phases. In an initial phase, a low level of know-how generates a low contribution in terms of new patents. In an intermediate phase a raising in know-how leads to a boost in patents. Once the know-how is close to reach its maximum value, the increase in the number of patents amplifies only marginally.

In order to overcome the above limits, a dynamic resource-based approach is proposed to investigate the concept of IC.

\section{Investigating intellectual capital through a 'dynamic resource- based perspective'}

\subsection{The proposed definition of IC}

On the basis of the above remarks, a perspective aimed at investigating the nature of IC may contribute to provide some lights to better understand its concept. The term "intellectual" comes from the Latin intelligere, i.e. to understand, to learn. The term "capital" refers to investments in tangible or intangible production factors, leading to an expectation of future yields.

Consequently, IC should be related to those investments done by a firm to improve the learning processes of its people and of the organisation itself to understand how to coherently set ends/goals with current and desired means to achieve company targets. Such learning processes refer to the capability of an organisation to better frame the system in which the firm operates and decisions are made, and to identify the endowment of strategic resources (means) to be acquired or built for the achievement of firm ends/goals (Figure 3).

Figure 3 - The concept of Intellectual Capital

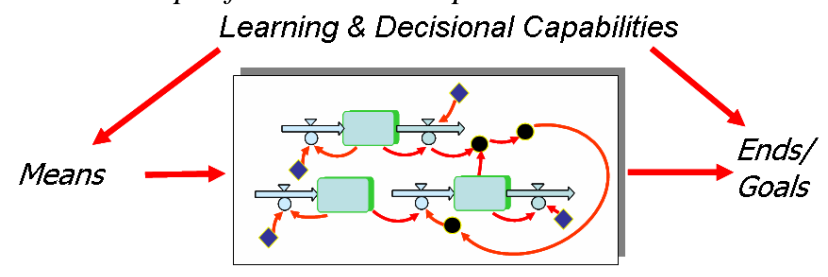

The suggested IC concept does not only relate to individuals' or business' 
know-how, i.e., the attitude to identify proper resources to achieve desired goals. It also applies to: the know-what and know-why (Garud, 1997). The concept of know-what refers to the attitude to detect specific subjects or issues on which to be focused (Kogut \& Zander, 1992). The concept of know-why is, instead, related to the understanding of cause and effect relationships between issues and events related to business performance, as a result of a learning process which shapes the way of thinking of individuals and the company.

Therefore, investments in education and human resource development (leading to human capital accumulation) are only some key-factors of IC. IC also consists of structural capital, which results from the process of individual knowledge elicitation, in order to act on human capital as a lever to build up business knowledge (Edvinson \& Malone, 1997). Moreover, investments aimed to build strong and long term relationships with external counterparts (e.g. customers, suppliers, competitors) give rise to a shared knowledge system, which may relate to products, information, distribution systems, etc. This is the so called customer or relational capital (Stewart, 1997).

From the above-mentioned analysis, it emerges that IC is a primary strategic asset to foster business growth and to achieve a superior business performance.

\section{From a static to a Dynamic resource-based perspective}

A recurrent approach to explain superior business performance on the basis of unique, difficult to imitate and non-substitutable tangible and intangible assets is the Resource Based View (RBV) of the firm (Penrose, 1959; Wernerfelt, 1984; Barney, 1991; Grant, 1991; Peteraf, 1993; Makhija, 2003).

This perspective outlines the firm as a complex bundle of resources, and it explains differences in companies performances based on the assumption that successful organisations possess strategic resources (physical, human and organisational) that competitors do not hold (Amit and Schoemaker 1993; Peteraf, 1993; Szulanski, 2003). Therefore, firm competitive advantage does not result from the industry dynamics; indeed, it stems from the process of accumulation and exploitation of firm strategic resources.

However, also the RBV shows some limits to be addressed.

First, it is difficult to identify which firm's strategic resources represent key factors to achieve a superior performance (Porter 1991; McGrant, 1996; Mosakowski and McKelvey, 1997).

Second, the focus of the analysis at the firm level is likely to disregard the industry context (D’Aveni, 1994; McGrant, 1996). In a hypercompeti- 
tive environment, firm outcomes result from the interaction of many internal and external forces.

Third, balancing investments in new knowledge acquisition (strategic resource exploration) with those oriented to use the knowledge already acquired (exploitation) often gives rise to a myopic focus on exploitation (March 1991; Levinthal and March, 1993). Such phenomenon results from an emphasis on the current resources endowment, which is perceived by decision-makers as appropriate to frame the past, but not necessary for the present or the future ${ }^{2}$ (Hamel and Prahalad, 1994). Consequently, opportunities and threats interpreted through frames based on current resources endowment, rather than a dynamic analysis of resource accumulation and depletion processes - resulting from management policies - can lead to systematic errors in resource allocation decisions (Amit and Schoemaker, 1993).

This behaviour can be also due to a lack of methods and tools (Bontis, 2002) which may enable decision makers to investigate organisation strategic resources acquisition and decline processes that control them and drive their evolution over time, thereby influencing firm performance (Warren, 2002; 2005; 2008; Morecroft, 1997; 2002; Reed at al., 2006). The relevance of such concepts has been introduced into strategy literature by Dierickx and Cool (1989) along with the bathtub metaphor reported in figure 4 (Morecroft, 2002).

Figure 4 - Accumulation and the depletion processes underlying strategic assets dynamic

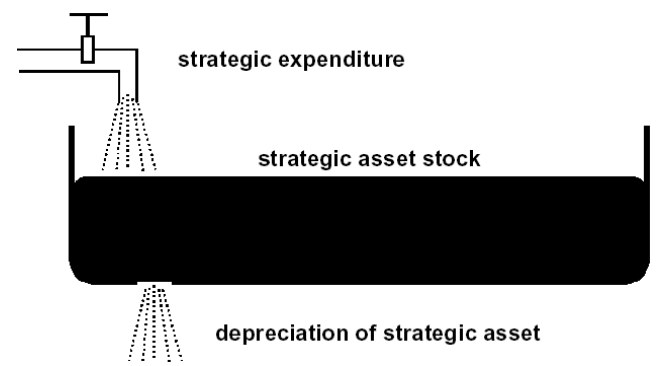

Source: Morecroft 2002, p. 21.

\footnotetext{
${ }^{2}$ Such a myopic approach has been also remarked by Hamel and Prahalad (1994). They argue that a firm has a "corporate genetics" (that is beliefs, values, norms, managers know how, biases and assumptions about the structure of the relevant industry, about who the customers are or are not, etc.) that - when environment changes rapidly and radically - may become a threat to survival. In order to effectively cope with such phenomenon, firms must create within themselves a reasonable portion of "genetic diversity" and selectively "unlearning the past". Managers should question their beliefs and their frames and recognise that Intellectual capital depreciates over time and there is the need to continuously rebuild it.
} 
The "bathtub" metaphor points out the importance to focus on the accumulation and depletion processes affecting strategic assets dynamic. As remarked by Dierickx and Cool (1989) "while flows can be adjusted instantaneously, stock cannot. It takes a consistent pattern of resource flows to accumulate a desired change in strategic asset stocks". Investigating such processes is particularly relevant for non-tradable strategic resources (such as, firm reputation, human capital, customer base loyalty), as they result from a given set of investment policies adopted by a firm over time.

The "bathtub" metaphor clearly differentiates the stock from the in-andout flows. The stock variable represents the level of water in the bathtub in a moment of time and it is the cumulative result of the continuous flow of water into the tub, net of the outflow of water. By acting on the tap, decision makers define a policy to influence the water inflow. Water outflow results from a "normal" decline process, which can be also referred to an explicit decision to empty the bathtub. Such a perspective shifts the focus of the strategic analysis from a static toward a dynamic investigation of resources accumulation and depletion processes.

To cope with the above-mentioned remarks the use of the System Dynamics (SD) is suggested (Forrester 1961; Sterman 2000). SD is a method to enhance learning in complex systems. This approach adopts an endogenous perspective to search for the main causes of the investigated phenomenon, rather than an exogenous view. This constitutes one of the main assumptions of the SD methodology: the dynamic of a given phenomenon is a consequence of the internal feedbacks structure. Feedbacks, i.e., closed relationships between cause-and-effect variables, are important to investigate as they make explicit and more communicable the dynamic hypotheses on how a system works (Richardson and Plug, 1981). Feedbacks analysis also allow to test decision makers' mental model beliefs.

Feedback loops diagrams represent a first step in applying the SD methodology ${ }^{3}$. They are considered a very effective tool to provide qualita-

\footnotetext{
${ }^{3}$ The process of building a SD model is usually distinguished in sequential stages (see Richardson and Plug, 1981). It starts with problem identification and model purpose. Main causal relationships between main variables are then outlined in feedback loop diagrams. The next step aims to make explicit stock and flow diagrams, which can provide the basis to develop a management flight simulator and run alternative scenarios. To built a stock and flow diagram a number of tasks are required: (a) model formulation and calibration of parameters (i.e., data and information are collected and estimated to feed the simulation model), (b) analysis and test of portrayed behaviour of model variables (i.e., through simulation runs the ability of the model to replicate an initial reference behavior of the phenomenon under investigation is tested), (c) model evaluation (i.e., model formulation coherence is
} 
tive insights into the behavior of the investigated phenomenon. However, very often the high system complexity may prevent a fully understanding of results generated by alternative policies. For this reason formal simulation models are developed.

Based on the results of the feedback loops analysis, simulation models are then built. Such models use stock and flow diagrams to outline accumulation and depletion processes underlying firms tangible and intangible strategic resources. Stock and flow diagrams are then usually embodied in management flight simulator environments to allow decision makers to test ex-ante the effects of their decisions on business performances over time (Morecroft 2007; Warren 2008; Gary 2005; Hafeez and Abdelmeguid, 2003). The use of SD simulation models also revealed their contribution to build a constructive dialogue inside corporations in evaluating the impact of alternative strategies on firm performance. Through such an approach, "managers could understand better the trajectory of the value creation from a given strategy, and they could fully evaluate strategic alternatives before committing resources for new investments" (Norton and Kaplan, 2001).

Figure 5 - A System Dynamics stock and flow diagram capturing strategic asset accumulation and depletion processes and managerial policies

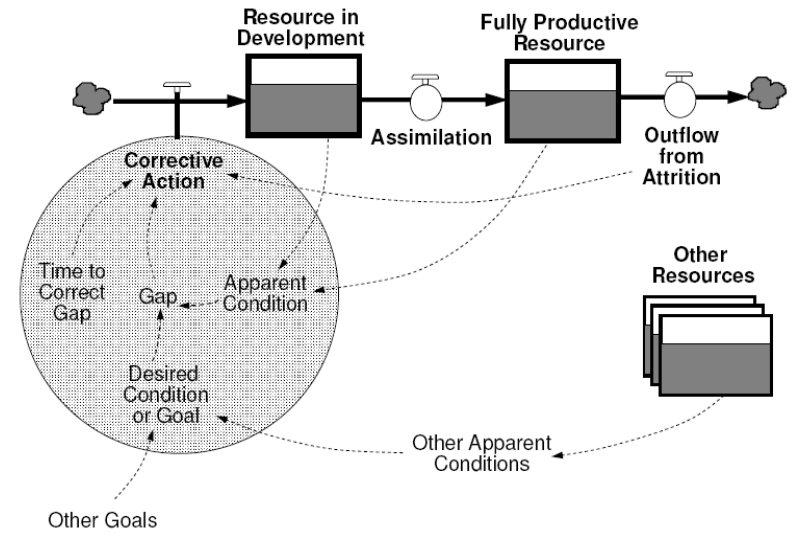

Source: Morecroft 2002, p. 22.

tested with the investigated phenomenon), (d) policy analysis and implementation (i.e., alternative policies are tested to identify which produces the best results for implementation in the system). In such a process, the group model building approach (Vennix 1996), facilitating the deep involvement of main key-actors operating inside the investigated context, is likely to enhance learning in the organization and to foster consensus and commitment with the outcomes. 
Figure 5 displays in the upper part the accumulation and depletion processes of a given strategic resource. The two rectangles connected through an arrow represent a stock variable. The first stock is influenced by an inflow variable 'corrective action', which is the result of a given managerial policy. For instance, if the stock variable refers to company 'new hired human resources', the inflow variable affecting such a stock is the 'hiring rate'. The intermediate flow between the two stocks expresses the process through which a given resource becomes fully productive (for instance, from 'new hired human resources' to a 'trained human resources' stock). A strategic resource deterioration process can be also made explicit through an out-flow variable (outflow from attrition).

At the bottom of figure 5, it is possible to detect a feedback relationship characterising the managerial policy aimed at achieving the desired strategic resource condition or goal. If the 'desired strategic resource or goal' differs from the 'apparent condition' a gap is made explicit and it drives the adoption of a 'corrective action' aimed to bridge such a gap. It is worth noting that the desired goal is compared with the "apparent" condition rather than the "actual" one of a given resource. This may due to delays embodied in the information systems or people's cognitive limitations in keeping into account all relevant data in a given moment (Simon 1979).

The use of simulation models, based on stock and flow diagrams, allows decision makers to simulate ex-ante, in a virtual and safe environment, alternative policies aimed at achieving desired goals before committing resources for new investments. By investigating simulation results it is possible to support decision makers' learning processes and to question their mental models about the real causes underlying strategic assets dynamics.

In order to build a SD model to explore IC accumulation and depletion processes and their impact on firms performance the "instrumental perspective" has been adopted (Bianchi, 2012). Such a perspective aims to outline the relationships between 'end-results', 'performance drivers', 'strategic resources' and 'policy levers' on which decision makers can act to achieve desired goals ${ }^{4}$.

\footnotetext{
${ }^{4}$ The instrumental perspective together with the objective (e.g., the relationship between external/internal products, processes and underlying activities) and the subjective (e.g., responsibility areas and associated goals and results) views are the three building blocks of a dynamic-performance management system (Bianchi, 2012).
} 
Figure 6-The "Instrumental" view of the performance

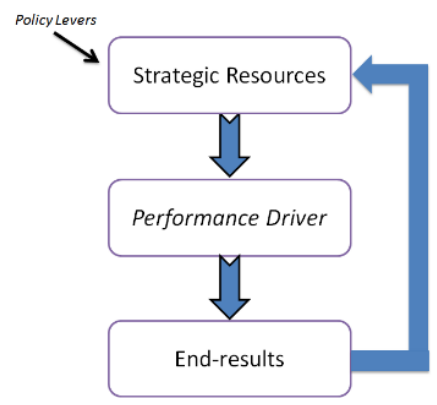

Source with changes: Bianchi 2012, p. 153.

According to the "instrumental view" company end-results, performance drivers and strategic resources are interconnected through a cause-and-effect chain.

Once decision makers clearly identify company end-results (for instance, customers), it is necessary to discern those "drivers" able to affect organisation end-results. Performance drivers are associated with critical success factors which play a crucial role on the behaviour of firm end-results. They are not measured in absolute terms, but instead in relative ones by taking into account competitors performance, the industry standard or a desired target.

For instance, with reference to an insurance firm, the end-result "new customers" can be the effect - among the other critical success factors - of the driver "time to settle claims ratio", which results from the ratio between "company's time to settle claims" and "competitors' time to settle claims" operating in the same competitive arena. This implies that a company time to settle claims lower than competitors - all other conditions being equal - drives an increase in the company competitive position and, consequently, in "new customers". Such a positive change in the number of customers, in turn, gives rise to the company strategic asset "customers".

On the basis of the above-mentioned remarks, end-results cannot be directly changed by decision makers. Therefore, they can be only influenced by performance drivers. However, performance drivers are affected by company strategic resources in a given moment of time. Such strategic assets endowment can be accumulated or depleted over time through decision makers' or competitors' policies and they can be also modified by end-results flows.

The use of the instrumental approach also allows to cope with one of the main critics of the internal perspective adopted by the RBV. In fact, by making explicit the role of the performance drivers it is possible to identify those criti- 
cal success factors which are likely to foster the acquisition of a sustainable competitive advantage.

In the next section, the here above discussed conceptual framework to investigate IC accumulation and depletion processes was applied to an insurance firm.

\section{Investigating IC accumulation and depletion processes through a dynamic resource-based perspective in an insurance firm}

\subsection{Research methodology and project outline}

In order to investigate how investment policies affect IC accumulation and depletion processes and how IC is likely to influence the performance of the organisation over time a case-study research approach was selected. The case-study research aims to gain a rich understanding of the investigated context and to provide an answer to questions such as why, what and how (Robson, 1993: 44).

The framework reported in the previous pages was applied to the Nonlife Insurance (NLI) ${ }^{5}$, an European insurance firm operating in Italy.

NLI was selected to conduct a one-year research project for two main reasons. First, as the organisation is an insurance firm, it is characterised by a high intensity of human capital and the performance of the organisation is strongly linked to IC investments. Second, the management already knew the concept of IC and showed a high level of interest to explore how IC assets dynamics can impact on the performance of the organisation through a System Dynamics model.

NLI key-areas personnel (e.g., commercial, marketing, finance, human resource management and training, claims, research and development, and information systems) was involved during all four phases of the SD model building process (Vennix, 1996).

In the first step, an analysis of company background and main critical success factors was carried out. Data collection was conducted through documentary analysis, personnel interviews and half day workshops with company personnel. These activities provided the basic information on how the firm operates, what the critical success factors are, why given strategies are identified and desired goals set.

\footnotetext{
${ }^{5}$ The name of the firm has been disguised for confidentiality reasons.
} 
In the second step, the "instrumental perspective" previously discussed was applied to NLI to make explicit the relationships between policy levers, strategic resources, drivers, end-results and performance indicators (see figure 7).

In the third step, IC accumulation and depletion processes were investigated through the lens of the SD methodology. According to such a view, the relationships between strategic resources accumulation and depletion processes, drivers, end-results and performance indicators were presented in the form of a stock-and-flow diagram. The simulator resulting from group model building sessions (Vennix, 1996) with company personnel was then calibrated on past behaviours of business key-variables.

The stock and flow structure was then embodied in a management flight simulator environment. It consists of three main areas:

- an introduction, including a user guide on how to use the simulation model and a short presentation of the case study;

- a control panel interface, embodying main policy levers related to the investigated areas, alternative scenarios variables and input parameters (e.g., initial values of the variables embodied in the SD model);

- reports, including graphs and reports windows of main variables impacting on company operations, IC and financial results.

In the fourth step, the SD model was initially validated through structural and behavioural analyses (Forrester and Senge, 1980; Barlas, 1996) and tested with the NLI personnel who participated in the development of the model.

\subsection{Brief NLI company introduction}

NLI is a European insurance company operating in Italy in the consumer market dealing exclusively with accident insurance.

The company market share is $3 \%$. It has 25 sales managers coordinating about 500 agencies and 180 damage appraisers. The personnel is considered highly qualified in the industry where NLI operates.

Agencies receive an average 10\% commission (equal to competitors' commission) on the premiums paid by customers. Commission plays an important role in the Agency/Company relationship. Although, on one side, it significantly affects the profitability of the company; on the other side, it allows NLI to build a long term relationship with agencies, which in most cases lasts more than thirty years. An annual $2 \%$ commission is also paid to agents when desired sales goals are matched. 
NLI adopts structured training programs for all employees.

Sales managers are divided into junior and expert (with more than 2 year of experience in the industry) categories. Newly hired sales managers are first trained for 10 days, and then receive on average a period of 30 days on-the-job training by more experienced sales managers. Twice a year, expert sales managers attend training courses designed to bring their skills and knowledge up to date. These courses usually lasts 5 days.

Damage appraisers are divided into three different categories:

- Junior, newly hired personnel handling easy claims;

- Senior, personnel with 2 year of experience in the industry, and;

- Expert, personnel usually with operation and coordination tasks.

The newly hired damage appraisers go through classroom training (30 days), followed by on-the-job training (30 days). Senior and expert damage appraisers are also trained for 5 and 2 days a semester, respectively. In terms of career development plan, it usually takes 2 year for a junior claims adjuster to become senior. To boost damage appraisers productivity NLI uses to provide incentives, which may vary from low, medium to high.

In the next four years, the company is expected to achieve a $4.5 \%$ market share and to enlarge the agencies up to 570. The company also aims to reduce of 1 or $2 \%$ the combined ratio (Total costs / company premiums), which is currently around 0.98 .

\subsection{Applying the "instrumental perspective" to NLI}

From the company analysis two desired goals emerged: an increase in market share from $3 \%$ to $4,5 \%$ and a decrease in the combine ratio of 1 or 2 percent. Such performance indicators, together with return of investments, return on equity and the combined and loss ratio (total losses incurred in claims divided by the total premiums earned) are displayed at the bottom of figure 7 .

Figure 7 aims to depict the relationships between performance indicators, end-results, drivers, strategic resources and policy levers. To better understand the contribution of such a framework and to support decision makers in outlining the impact of IC investment policies, it should be read bottom-up. In fact, by looking at performance indicators and end-results decision makers can only detect ex-post results of previous applied policies.

Based on the analyzed case, in order to support NLI to reach the desired goals, decision makers cannot act directly on company end-results, such as new customers, revenues, net income, operating income, customers lost, change in company image and agencies turnover. 
They have to make explicit the main drivers leading to a change on the above-mentioned results. In other words, critical success factors leading to a sustainable competitive advantage have to be identified and compared with competitors or industry standards. On the basis of the NLI competitive analysis carried out, it is possible to identify the following performance drivers:

- Time to Settle Claims (i.e., the ability of NLI to settle claims in a short period of time);

- Damage appraisers Efficacy and Efficiency (i.e., NLI human resources ability to correctly and promptly assess the claim value);

- Agencies / SM (i.e., the ability of an organisation to grant a support by sales managers to agencies);

- Innovativeness (i.e., company's capacity to constantly update products);

- Product Portfolio Quality (i.e., ability of the firm to promptly launch new products on the market);

- Customer Service (i.e., the service level perceived by customers).

All the above drivers have to be measured not in absolute terms, but instead in comparison with the industry standards or competitors performances. In fact, only a NLI Time to Settle Claims lower than the industry standard or main competitors performances is likely to improve organisation end-results and, consequently, performance indicators.

As previously described for the end-results, also drivers cannot be directly influenced by decision makers. For instance, to improve company competitive position in terms of time to settle claims or Innovativeness, decision makers should identify those strategic assets that are likely to influence the investigated drivers.

Among such tangible and intangible strategic resources, it is possible to remark, for instance, the "number of damage appraisers", "human resource knowledge" and "organisational structure \& information systems quality". Strategic resources can be acquired externally or accumulated internally. For instance, "new damage appraisers" can be hired from other organizations. Human resource knowledge, instead, can only built internally, for instance, through training policies.

It follows that, in order to act on strategic assets accumulation and depletion processes, decision makers have to identify those policy levers able to influence their dynamics over time.

It is worth remarking that strategic resources accumulation and depletion processes can also be influenced by end-results. This is, for instance, the case of company customers, which vary through "new customers" and "customer lost". 
Figure 7 - A conceptual framework to outline the impact of IC investment policies on strategic resources, drivers, end-results and performance indicators in an insurance firm.

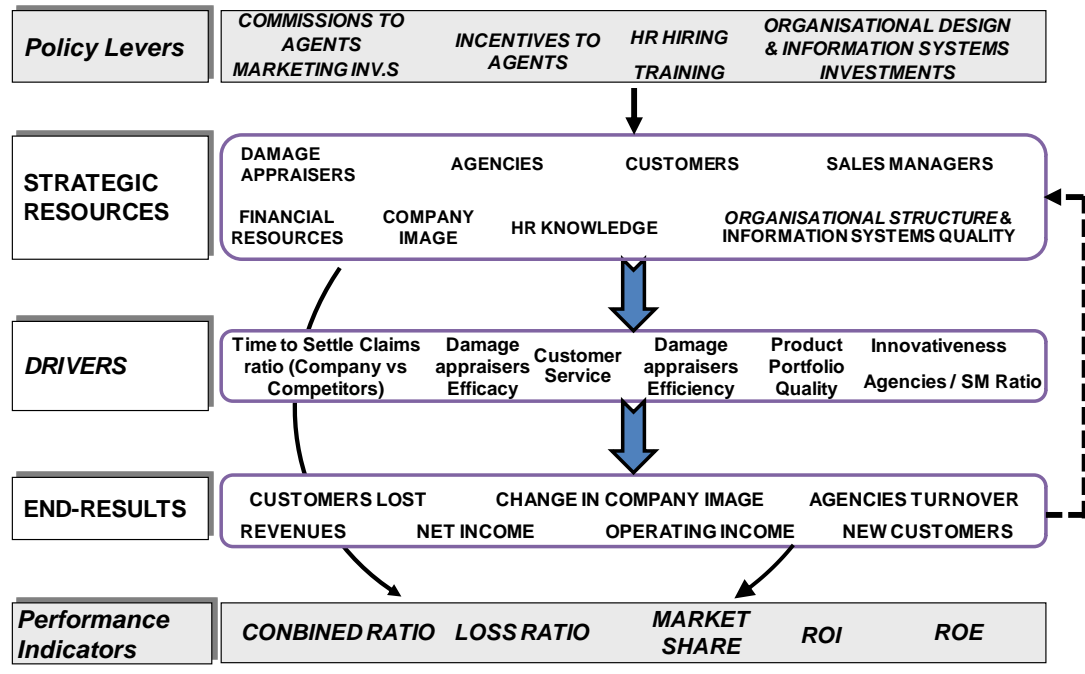

On the basis of the conceptual framework reported in figure 7, IC strategic assets can be identified in terms of "human resource knowledge" and "organisational structure \& Information systems quality".

The above analysis makes also explicit the cause-and-effect relationships driving the performance of the firm. A simplified picture of the main feedback loops is reported in figure 8 .

Figure 8 depicts four different feedback loops, two of them are reinforcing (R1 and R2) and the remaining balancing (B1 and B2). R1 aims to capture the effects generated by training investments on Human Resources (HR) knowledge index, which in turn is likely to give rise a high product portfolio quality ${ }^{6}$. As a consequence of a boost in product portfolio quality, company image and customer base tend to grow. A large customer base generates an increase in sales revenues, and additional financial resources can be allocated to sustain new training investments. However, such a reinforcing growth process generated by increasing HR training investments over time may face a limit due to the raise in claims and, consequently, in time to settle claims. A deterioration of such a driver deteriorates the customer service, which in turn determines a decline in company image and customer base. A reduction in customer

\footnotetext{
${ }^{6}$ Here it is assumed that qualified human resources improve the product portfolio quality, as they are able to launch new products matching customers' needs.
} 
base is likely to generate a fall in the number of claims and to restore the time to settle claims to an acceptable level. Based on such remarks, the abovecommented relationships portrays a balancing feedback loop (B1). In order to bring the time to settle claims to a desired value, the company can bridge such a gap by hiring new damage appraisers, which in turn can contribute to minimize the time to settle claims. This feedback also underlies a balancing loop (B2), as it aims to push the time to settle claims towards a given value able to foster business growth. This phenomenon can be also amplified as result of the investments in HR training. In fact, such investments by increasing the knowledge and the skills of organization's HR (i.e., HR knowledge index) can bring the time to settle claims down (see reinforcing feedback loop R2).

Figure 8 - Main feedback loops related to the insurance company

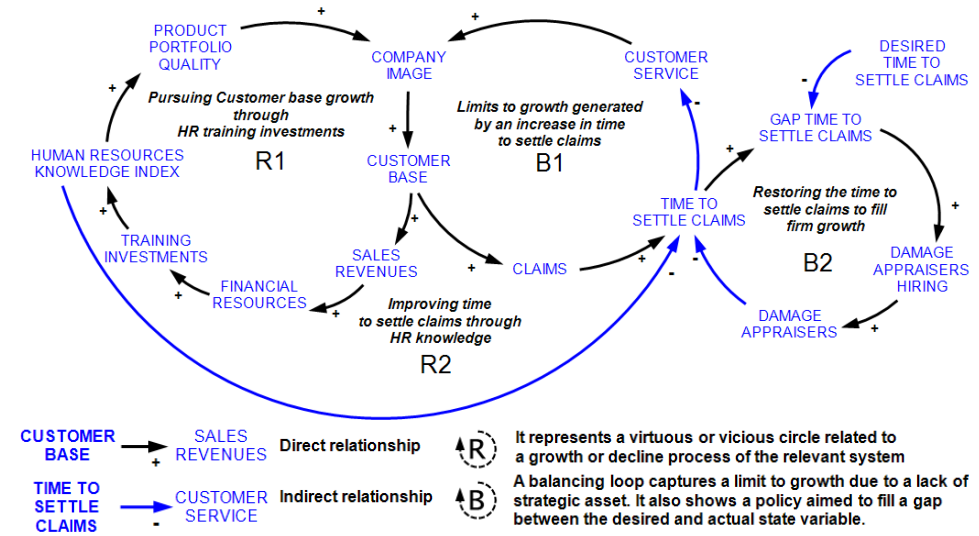

In the next session, the results of two alternative IC investments policies through the use of the above discussed SD model are commented.

\section{Concluding remarks}

As highlighted in the literature review of IC frameworks reported in the first part of the paper, such approaches are remarkable for the authors' efforts to identify homogeneous families/categories of intangibles and related indicators to gauge the performance inside each single area (Edvinsson and Malone, 1997; Sveiby, 1997). To overcome the main critics to set a coherent number of indicators to measure IC, a value chain approach focused on the process of knowledge generation was also proposed (Lev, 2001). Other approaches (MERITUM, 2002; DMSTI, 2003), to successfully implement a given strate- 
gy, suggested to analyse the actions and initiatives required to built a desired endowment of intangible assets. More recently, cause-and-effect relationships between IC strategic resources and organisation value creation were made explicit through a value creation map (Marr et al., 2004).

However, although the above frameworks significantly contributed to make relevant advancements on how to measure and link IC to the performance of an organisation, main drawbacks still persist in favouring a static rather than a dynamic perspective in investigating IC investments. This is a crucial point to effectively support decision makers to understand how to evaluate the effects generated by IC investments over time.

To this end, this paper aims to show the benefits deriving from the adoption of a Dynamic Resource-based perspective in investigating the cause-and-effect relationships underlying IC accumulation and depletions processes. Similar to previously discussed approaches, Dynamic Resource-based perspective adopts a process perspective in making explicit the relationships between performance indicators, end-results, drivers and strategic resources. Additionally, the use of System Dynamics-based simulation models enables decision makers to test in a friendly environment alternative IC investment plans and to improve their understanding of the investigated system.

To build a sustainable competitive advantage, IC investments should be planned taking into account human resource knowledge accumulation and depletion processes. In fact, an unbalanced resource allocation policy - between commercial, human resources and organisational structure - may prevent the achievement of the desired goals.

Additional empirical researches are necessary to validate the conceptual framework developed through the dynamic resource-based perspective and applied to an insurance company. Such studies, in the same and in other related knowledge-intensive industries, can contribute to better understand IC accumulation and depletions processes and to improve decision makers' learning processes in IC planning setting.

\section{References}

Amit R., Schoemaker P. (1993), Strategic Assets and Organizational Rent. Strategic Management Journal 14: 33-46.

Andriessen D. (2004), Making sense of Intellectual Capital. Design a method for the valuation of Intangibles, USA, Elsevier Butterworth-Heinemnn, Burlington.

Barlas Y., (1996), Formal aspects of model validity and validation in system dynamic. System Dynamics Review, Vol. 12, no. 3 
Barney, J. B. (1991), Firm resources and sustained competitive advantage. Journal of Management, 17: 99-120.

Bianchi C. (2012), Enhancing Performance Management and Sustainable Organizational Growth through System Dynamics Modeling, in: Groesser S. N., Zeier R. (Eds.), Systemic Management for Intelligent Organizations: Concepts, Model-Based Approaches, and Applications, Springer-Publishing, Heidelberg

Bianchi C. and Bivona E. (2005), Using System Dynamics ILEs to enhance Intellectual Capital policies in service businesses. Paper presented at the annual International System Dynamics Conference, Boston.

Bivona E. (2008), Exploring Intellectual Capital in a call centre through a 'System Dynamics' resource based view, Portuguese Journal of Management Studies, Vol. XIII, N. 3, 361-384.

Bontis N. (2001), Assessing knowledge assets: a review of the models used to measure intellectual capital. International Journal of Management Reviews, 3(1), 41-60.

Brooking A. 1996. Intellectual Capital. International Thompson Business Press: London.

C. Choo and N. Bontis (2002), The Strategic Management of Intellectual Capital and Organizational Knowledge, New York, Oxford University Press.

Dierickx I, Cool K. (1989), Asset Stock Accumulation and Sustainability of Competitive Advantage. Management Science 35(12):1504-1511.

DMSTI 2003. Intellectual Capital Statements - The New Guideline, Danish Ministry of Science, Copenhagen, Technology and Innovation.

Dumay JC (2009), Intellectual capital measurement: a critical approach. Journal of Intellecual Capital 10(2), 190-210.

Edvinson L, Malone M. (1997), Intellectual Capital. New York, Harper business.

Forrester J.W. (1961), Industrial Dynamics, Productivity Press.

Forrester J.W., Senge P. (1980), Tests for building confidence in System Dynamics Models. TIMS Studies in the Management Sciences 14. North-Holland Publishing Company

Hafeez K and Abdelmeguid H. (2003), Dynamics of Human Resource and Knowledge Management, Journal of the Operational Research Society, 54:153-164.

Hamel G. and Prahalad C.K. (1994), Competing for the future, Boston, MA, Harvard Business School Press.

Hsu I.C. and Sabherwal R. (2011), From intellectual capital to firm performance: the mediating role of knowledge management capabilities. IEEE Transactions on Engineering Management, 58(4), 626-642.

Kaplan R.S. and Norton, D.P. (2001), The Strategy Focused Organization, Boston, Harvard Business School Press.

Kogut B, Zander U. (1992), Knowledge of the firm, combinative capabilities, and the replication of technology. Organization Science 3(3): 383-397.

Lev. B. (2001), Intangibles: Management, Measurement, and Reporting, Washington D.C.

Lönnqvist A., Sillanpää V., Carlucci D. (2009), "Intellectual Capital Management in Practice: Assessment of Implementation and Outcomes, Knowledge Management Research and Practice, Vol. 7, No. 4, pp. 308-316.

Marr B. (2005), Perspectives on intellectual capital. Multidisciplinary insights into management, measurement, and reporting (ed.). Oxford, Elsevier Buthherworth-Heinemann, Burlington.

Marr B., Schiuma G., Neely A. (2004), The Dynamics of Value Creation: Mapping your Intellectual Performance Drivers, Journal of Intellectual Capital, Vol. 5, No. 2, pp. 312325. 
Enzo Bivona

Menor L.J., Kristal MM and Rosenzweig E.D. (2007); Examining the influence of operational intellectual capital on capabilities and performance. Manufacturing and Service Operations Management, 9(4), 559-578.

Morecroft J. DW. (1997), The Rise and Fall of People Express: A Dynamic Resource-Based View. Proceedings of the 1997 International System Dynamics Conference. Barlas Y, Diker V, Polat S (eds.). Istanbul: 579-586.

Morecroft, J. DW. (2002), Resource Management under Dynamic Complexity, Chapter 2 in Systems Perspectives on Resources, Capabilities and Management Processes (eds Morecroft, Sanchez and Heene), Advanced Series in Management, Oxford: Elsevier Pergamon.

Morecroft, J. DW. (2007), Strategic Modelling and Business Dynamics. Chichester: Wiley.

Nørreklit H. (2000), The Balanced Scorecard - a critical analysis of some of its assumptions. Management Accounting Research 11, 65-88.

Pasher E., Ronen T. (2011), The complete guide to Knowledge Management. A strategic plan to leverage your company's Intellectual Capital, New Jersey, John Wiley \& Sons Inc. Hoboken.

Porter M. E. (1985), Competitive Advantage; Creating and Sustaining Superior Performance. New York, The Free Press.

Porter M. E. (1991), Towards a Dynamic Theory of Strategy, Strategic Management Journal, Vol. 12, Special Issue: Fundamental Research Issues in Strategy and Economics. (Winter), pp. 95-117.

Reed K. K., Lubatkin M. and Srinivasan N. (2006), Proposing and Testing an Intellectual Capital-Based View of the Firm. Journal of Management Studies, 43: 867-893.

Richardson G.P. and Plug A.L. (1981), Introduction to system dynamics modelling with DYNAMO, Cambridge (MA), MIT Press

Robson C. (1993), Real World Research: A Resource for Social Scientists and PractitionersResearchers, Oxford, Blackwell.

Rogers E. M. 1962. Diffusion of Innovations. NeThe Free Press. New York.

Roos G., Pike S., Fernstrom L. 2005. Valuation and reporting of intangibles - state of the art in 2004, Int. J. of Learning and Intellectual Capital, Vol.2, No.1, pp.21 - 48

Roos J., Roos G., Dragonetti N.C., and Edvinsson L. (1997), Intellectual Capital: Navigating in the New Business Landscape. Macmillan: London.

Simon H.A. (1979), Rational decision making in business organisations, American Economic Review, 69, 493-513.

Sterman JD. (2000), Business Dynamics - System Thinking and Modeling for a Complex World. Irwin McGraw-Hill.

Stewart T. (1997), Intellectual Capital. New York, Doubleday.

Sveiby K. (1997), The New Organizational Wealth. San Francisco, Berrett-Koehler.

Vennix J. (1996), Group Model Building. Wiley: Chichester.

Warren K. (2002), Competitive Strategy Dynamics. John Wiley \& Sons: Chichester.

Warren K. (2005), Improving strategic management with the fundamental principles of system dynamics. System Dynamics Review, 21(4): 329-350.

Warren K. (2008), Strategic Management Dynamics, England, John Wiley \& Sons.

Wernerfelt B. (1984), A Resource-based View of the Firm. Strategic Management Journal 5:171-180

Winch G. (2001), Management of the "Skills Inventory" in Times of Major Change. System Dynamics Review 17(2): 151-159. 